\title{
Research on Risk Assessment of City Natural Disaster Based on Neural Network
}

\author{
Xinyan Wu \\ Institute of Geophysics, China Earthquake Administration, Beijing, China
}

\begin{abstract}
Aiming at the selection of fuzzy AHP and fuzzy DH methods in the previous studies, this paper evaluate the qualitative index system using expert questionnaire, the self-learning BP neural network model to construct the index of system, and complete the establishment of model, in order to avoid the serious subjectivity, and using statistical and measurement methods test the reliability index, analyze the validity of the evaluation index system and completeness. Finally, the paper validate the practicability of the model.
\end{abstract}

Keywords-Geological disaster; Disaster prevention and mitigation; Neural network; Risk assessment

\section{GENERAL InStRUCTIONS}

Emergency management and capability assessment of city geological disaster is an important part of city emergency management, through the means of Science Effective evaluation of complete emergency management capability of city geological disaster can in order to improve the city emergency management the ability to specify the method and road. According to the degree of development of the current emergency management capability assessment for geological disasters at home and abroad, research the city, through the study of city emergency response system in geological hazards, vulnerability and city geological disaster emergency management ability, make use of quantitative index system to complete the evaluation of the ability of emergency management model of thinking, the other road of city geological disaster emergency management ability to do some groundwork. The research method of this article combines econometrics, BP neural network method, makes a deep research on the key city geological disaster emergency management, emergency management ability in defined areas within the completed model construction and self-learning process.

\section{The Structure AND PRINCIPLE Of NEURAL NETWORK EVALUATION MODEL}

(1) The structure of a neural network model

Because of BP neural network has own self learning, self-association and good tolerance, the index information usage patterns consistent with the scientific requirements in this study, specific conduction path and model structure is as shown in Figure 1.

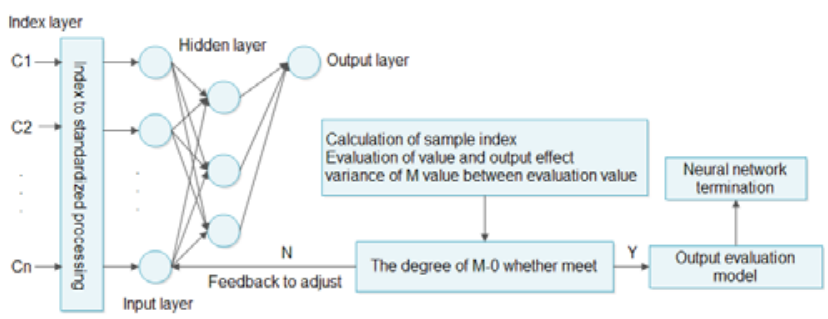

Figure 1. The structure diagram of artificial neural network

(2) Neural network model and its working principle

Neuronal activation values will be provided to the system in the learning samples from the output layer to the output layer through the hidden layer transfer, each neuron in the output layer finally obtain input response results of the system. In view of the network structures, the hidden layer neurons can be divided into type $\mathrm{S}$ or tangent incentive function, this paper adopts $S$ type excitation function of nonlinear networks, namely:

$$
f(x)=1 /\left(1+e^{-x}\right)
$$

(3) Learning model of artificial neural network

The self-learning function of BP neural network use conjugate gradient method, activation function of the input layer and the hidden layer is Tansig, the hidden layer activation function and the output layer using logsig, an upper parameters and excitation function constitute a whole network structure. Based on the algorithm of the neural network model, the optimization algorithm of the guiding ideology is: through the city in the process of construction and development of the society, optimize the propensity to pursue urban residents living level of security for city residents, or the study of emergency management personnel for emergency management capability assessment output of the city, the city construction process index calculated emergency management capability assessment level reaching the infinite.

Iterative steps of conjugate gradient method: a. provide $\bar{W}^{(0)}$ and the allowable error; b. after calculate $\vec{S}^{(0)}$ by $\vec{S}^{(0)}=-\nabla \mathrm{M}\left(\vec{W}^{(0)}\right)$

using $\bar{W}^{(k+1)}=\bar{W}^{(k)}+\lambda_{k} \vec{S}^{(k)}, \lambda_{k}=-\frac{\left[\nabla \mathrm{M}\left(\bar{W}^{(\mathrm{k})}\right)\right]^{T} \vec{S}^{(\mathrm{k})}}{\left[\vec{S}^{(\mathrm{k})}\right]^{T} A \vec{S}^{(\mathrm{k})}}$

to $\quad \vec{W}^{(t)} \quad$ calculate $\quad$;. $\quad$ using
$\vec{S}^{(\mathrm{k}+1)}=-\nabla \mathrm{M}\left(\vec{W}^{(\mathrm{k}+1)}\right)+\beta_{\mathrm{k}} \vec{S}^{(\mathrm{k})}$ 
$\beta_{k}=\frac{\left[\nabla \mathrm{M}\left(\bar{W}^{(\mathrm{k}+1)}\right)\right]^{T} \nabla \mathrm{M}\left(\bar{W}^{(\mathrm{k}+1)}\right)}{\left[\nabla \mathrm{M}\left(\bar{W}^{(\mathrm{k})}\right)\right]^{T} \nabla \mathrm{M}\left(\bar{W}^{(\mathrm{k})}\right)}$ until to get $\bar{W}^{(\mathrm{k})}$

and $\vec{S}^{(\mathrm{k})}$, so:

$$
\left\{\begin{array}{l}
\bar{W}^{(\mathrm{k}+1)}=\bar{W}^{(\mathrm{k})}+\lambda_{\mathrm{k}} \vec{S}^{(\mathrm{k})} \\
\lambda_{\mathrm{k}}=\operatorname{Min}\left(\bar{W}^{(\mathrm{k})}+\lambda_{\mathrm{k}}\right) \vec{S}^{(\mathrm{k})}
\end{array}\right.
$$

Wherein, $\lambda_{k}$ meet to the min value of $M\left(\bar{W}^{(\mathrm{k})}+\lambda_{k} \bar{S}^{(\mathrm{k})}\right)$; d. until to stop calculation of $\mid \nabla \mathrm{M}\left(\vec{W}^{(\mathrm{k})}\right) \|^{2}<\varepsilon, \bar{W}^{(\mathrm{k}+1)}$ is the final solution; Otherwise, if the $\mathrm{K}$ is not to $\mathrm{n}-1$, with (4) (5) to calculate $\beta_{k}$ and $\bar{S}^{(\mathrm{k})}$, and returns the $\mathrm{C}$ step, iterative center differential formula is:

$$
\partial M / \partial W_{j}=M\left(\omega_{1}, \ldots, \omega_{j}+\nabla \omega_{1}, \ldots, \omega_{n}\right)-M\left(\omega_{1}, \ldots, \omega_{j}-\nabla \omega_{1}, \ldots, \omega_{n}\right) / 2 \nabla \omega
$$

Process requires using MATLAB software to export model structure, realize the optimization of network and the training.

III. The Management Evaluation Model Of

City Geological DisAster Based On BP NEURAL NETWORK

1) Evaluation indexes of standard treatment for $B P$ neural network

Index selection is completed on the basis of target recognition process, after the selection of evaluation index system, index structure is as shown in fig.2.

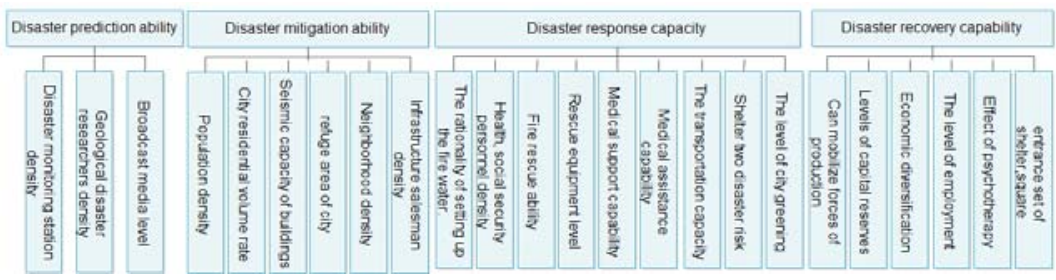

Figure 2. The evaluation index system of emergency management capability

After collecting a quantitative index, because the index have unit and dimension, therefore I need standardized the index and turn into dimensionless variables, then it can be used as the input index of the BP neural networks model to train. Using zscore () tools of Matlab standardize three level evaluation index data for emergency management capacity of geological disaster, standardization of data obtained are as shown in table 1.

TABLE 1 RESULTS OF THE STANDARD RELATED INDEXES IN DIFFERENT REGIONS

\begin{tabular}{ccccccc}
\hline Item & A Area & B Area & C Area & D Area & E Area & F Area \\
\hline Number of disaster monitoring station & 0.776769 & 0.505848 & 1 & 0.408132 & 0.041343 & 0 \\
Number of disaster monitoring & 1 & 0.228085 & 0.11626 & 0.289008 & 0.00272 & 0 \\
Broadcast media level & 0.774911 & 0.295339 & 0.063348 & 1 & 0.001098 & 0 \\
Population density & 1 & 0.643065 & 0.004261 & 0.222143 & 0.250195 & 0 \\
City residential volume rate & 1 & 0.659032 & 0 & 0.672096 & 0.584877 & 0.646391 \\
Seismic capacity of buildings & 0.738359 & 0.966131 & -0.03387 & 0.522873 & 0 & 0.107616 \\
City of refuge area & 0.673714 & 1 & 0.627159 & 0.886912 & 0 & 0.860715 \\
\hline
\end{tabular}

The paper establish an input layer contains 24 neurons, the first layer of hidden layer consists of 25 neurons, second layer consists of 4 neurons, the output layer consists of four layers BP neural network model, the input layer and the hidden layer activation function use Tansig, the hidden layer activation function and the output layer using logsig, in order to ensure the efficiency and effectiveness of neuron operation, set the maximum number of training is 1000, the goal of training is 0 , validation results after training in every 25 times, the minimum performance gradient value is 1e-006.
Through the observation in Figure 3, we be in the 113 time to train the network using conjugate gradient function, network error square and eventually reach the acceptable range of results, city emergency management capability assessment of geological hazards BP neural network model is established based on the neural network model, that can be an effective tool for training the ability of emergency management of different absolute city regional geological hazard assessment. 


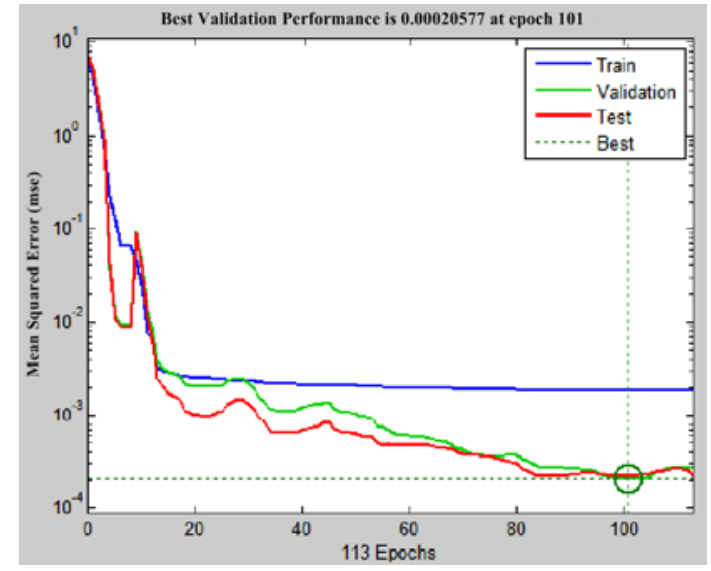

Figure 3. The training process of BP Neural network

After the training, we concluded standard evaluation index of city emergency management capability for four core capability that is as shown in table 2:

TABLE 2 THE RESULTS OF STANDARD INDEX FOR EMERGENCY MANAGEMENT CAPABILITY AFTER TRAINING

\begin{tabular}{cccccc}
\hline Area & A & B & C & D & E \\
\hline $\begin{array}{c}\text { Predictive } \\
\text { ability }\end{array}$ & 1 & 0.741026 & 0.641749 & 0.213144 & 0.530304 \\
$\begin{array}{c}\text { Slowing } \\
\text { abilities }\end{array}$ & 0 & 0.391209 & 1 & 0.281752 & 0.509113 \\
$\begin{array}{c}\text { Response } \\
\text { ability }\end{array}$ & 0 & 0.262276 & 1 & 0.14488 & 0.162286 \\
$\begin{array}{c}\text { Recovery } \\
\text { capability }\end{array}$ & 0.6707 & 0.529901 & 1 & 0.473214 & 0 \\
\hline
\end{tabular}

The training error is as shown in table 3 :

Model predictions for the test sample $\mathrm{X}$ area is as shown in Table 4

TABLE 3 THE TRAINING ERROR

\begin{tabular}{cccccc}
\hline Area & $\mathrm{A}$ & $\mathrm{B}$ & $\mathrm{C}$ & $\mathrm{D}$ & $\mathrm{E}$ \\
\hline Predictive & 0.0082 & 0.03365 & 0.021632 & 0.0027 & 0.0082 \\
ability & 27 & 21 & 656 & 22 & 27 \\
Slowing & -0.015 & -0.0281 & -0.025103 & -0.015 & -0.015 \\
abilities & 74 & 58 & 34 & 31 & 74 \\
Response & -0.035 & -0.0609 & -0.054987 & -0.032 & -0.035 \\
ability & 4 & 95 & 93 & 08 & 4 \\
Recovery & 0.0243 & 0.03892 & 0.025962 & 0.0170 & 0.0243 \\
capability & 77 & 95 & 232 & 58 & 77 \\
\hline
\end{tabular}

TABle 4 The Test Results Of X Region Based On BP Neural NETWORK

\begin{tabular}{cccc}
\hline F Area & Expect score & Training results & Relative error \\
\hline Predictive ability & 0.55781 & 0.584704 & -0.02689 \\
Slowing abilities & 0.963769 & 1.018001 & -0.05423 \\
Response ability & 0.687972 & 0.733212 & -0.04524 \\
Recovery capability & 0.59554 & 0.627257 & -0.03172 \\
\hline
\end{tabular}

\section{CONCLUSIONS}

The occurrence of geological disasters exist necessity and non-resistance, in the face of the forces of nature, human and social vulnerability is bigger, it can lead to the development of the natural disaster after the loss of more serious. With the rapid development of the city process, people often vulnerable to the development results of the blinded, leading to the city construction of short board, geological disasters will even cleared all the achievements of city construction, the city emergency management capability of geological disaster evaluation, makes us more clear understanding of the defects existing in the city development and construction and problems, and further propose suggestions to improve the city emergency management capability from every aspect..

\section{REFERENCES}

[1] Liang Youjia, Xu Zhongmin. Application of multivariate regression models of precipitation in Heihe River Basin Based on GIS [J]. Pratacultural science, 2011, 9:1581-1588.

[2] Tang Chuan, Liu Qiong Zhao.To explore the intensity and risk regionalization disaster China[J].Chinese Journal of geological hazard and control China, 1994, 5 (supp.): 30-35.

[3] Zhong Dunlun, Xie Hong, Wei Qiang Fang. Regionalization of Debris Flow Danger Degree in the upper reaches of the Yangtze River [J].Mountain research, 1994, 12 (2): 84-93.

[4] Liu Sifeng, Dang Yaoguo, Fang Z.G. Grey System Theory and Its Applications [M]. Beijing: Science and Technology Press, 2004, pp.415.

Wu Aiyou. City Fire Risk Evaluation of neural network and genetic algorithm based model [J]. China Safety Science Journal, 2006, 16 (11): 108-113. 